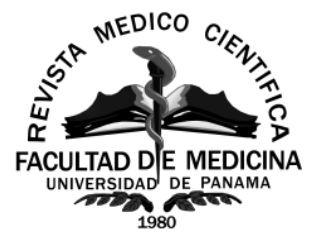

Revista Médico Científica, Vol. 34, Núm. 1: 19-20, 2021 ISSN 2218-8266/ISSN-L 1608-3849

\title{
Liquenificación perioribitaria a causa de un delirio de infestación
}

\section{Perioribitary liquenification due to delusional infestation}

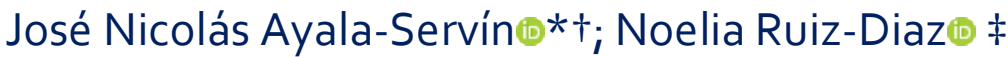

* Médico Residente de Psiquiatría Clínica, Universidad Nacional de Asunción. Paraguay

† Investigador Asociado, Universidad María Auxiliadora. Paraguay

¥Médico Especialista en Psiquiatría Clínica. Universidad Nacional de Asunción, Paraguay

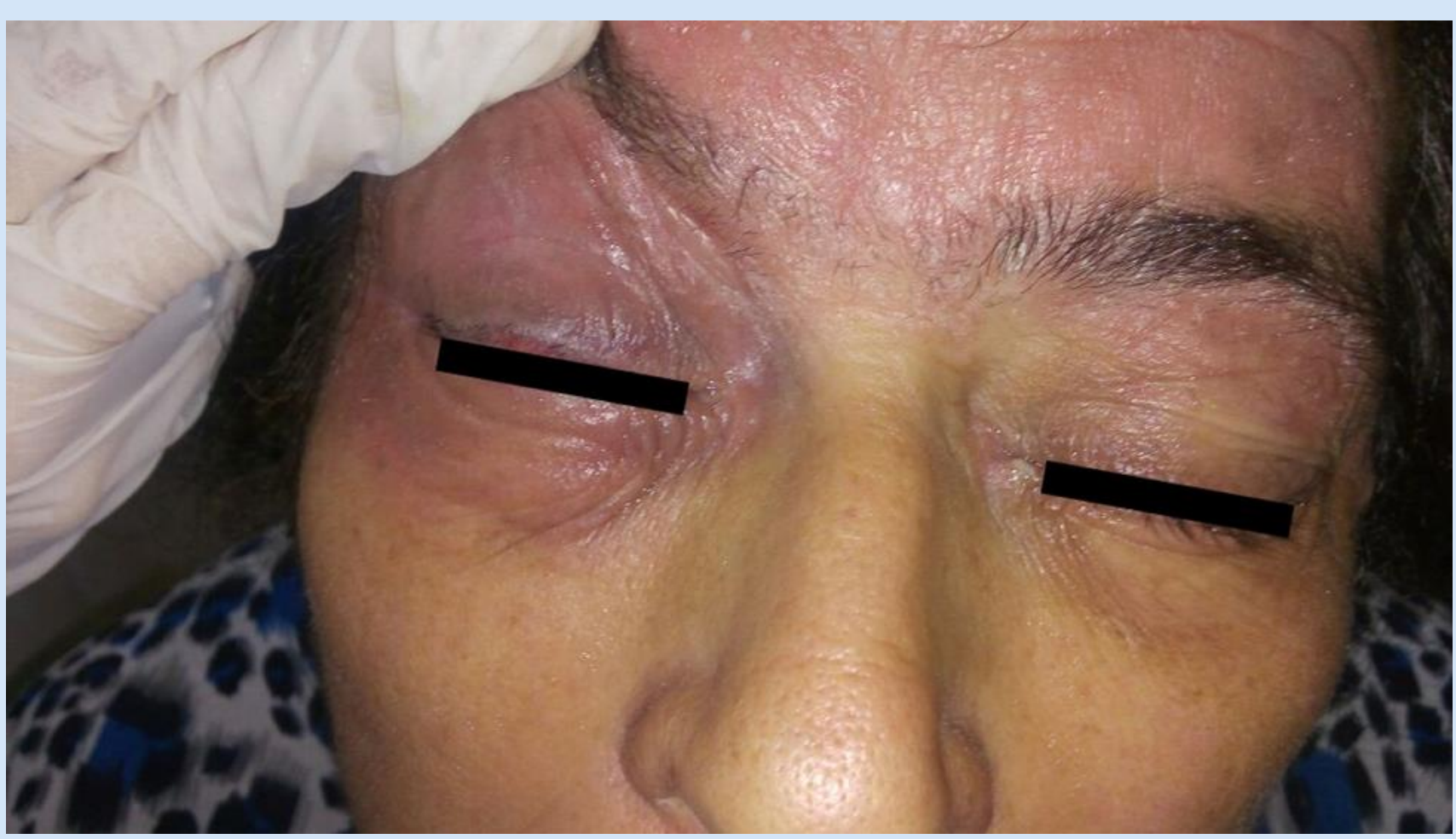

Figura 1. Liquenificación periorbitaria a consecuencia de delirio de infestación: Paciente evaluada en el Hospital de Clínicas (Paraguay) que presenta signos de liquenificación por rascado masivo en zonas periorbitarias y frontal de la cabeza, también se observa blefaritis derecha y ausencia de pestañas del mismo lado a causa del rascado como consecuencia de los delirios de infestación. La paciente presentó buena respuesta al antipsicótico atípico (Risperidona $3 \mathrm{mg}$ ) como inicio del tratamiento donde las ideas delirantes fueron disminuyendo en intensidad y frecuencia. Fuente: Servicio de Psiquiatría del Hospital de Clínicas (Asunción, Paraguay).

Correspondencia: nicoayala131292@gmail.com Recibido: 01/03/2021 Aceptado: 03/05/2021

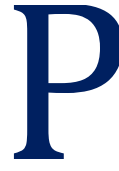

aciente de sexo femenino de 53 años acude a urgencias del Servicio de Dermatología del Hospital de Clínicas (San Lorenzo, Paraguay) para evaluación, posteriormente es evaluada por profesionales del Servicio de Oftalmología y tras descartar cuadro de organicidad, es derivada al Servicio de Psiquiatría para mejor manejo. 
La paciente refiere cuadro de 6 meses de evolución de delirios de infestación (por parasitosis en piel) y alucinaciones somáticas "tengo gusanos en mis ojos y debajo de mi piel". Se observan signos de liquenificación por rascado masivo en zonas periorbitarias y frontal de la cabeza, también se observan blefaritis derecha y ausencia de pestañas del mismo lado a causa del rascado (Ver Figura 1). Niega cuadro similar anterior. Niega hipertensión, diabetes mellitus, asma y alergias; niega antecedente de convulsiones o traumatismo craneoencefálico; niega antecedentes de cirugías e internaciones previas; niega consumo de alcohol, tabaco u otras sustancias ilícitas. Tratamiento de mantenimiento utilizando risperidona $3 \mathrm{mg} / \mathrm{dL}$ vía oral con buena evolución por parte de la paciente, donde las ideas delirantes disminuyeron en intensidad y frecuencia desde la semana de inicio de tratamiento y luego siguió el mismo curso de manera progresiva. Una vez disminuidas las ideas delirantes, se inicia acompañamiento psicoterapéutico (Terapia Cognitivo Conductual) con la paciente para mejor manejo. Con relación al rascado masivo, disminuyeron los episodios de forma concomitante a la extinción de las ideas delirantes y se determina como impresión diagnóstica de la paciente: Trastorno de Ideas Delirantes Persistentes. Con relación a las lesiones en piel, la paciente realizó seguimiento con el Servicio de Dermatología donde le indicaron cremas humectantes y corticoides para mejor tratamiento con respuesta favorable y sin dejar secuelas permanentes en las zonas afectadas.

En el delirio de parasitosis los pacientes no sólo manifiestan afección por parásitos, sino también por otros microorganismos como bacterias, virus $y$ cuerpos extraños. ${ }^{[1]}$ El delirio por parasitosis se refiere a un cuadro psicótico inespecífico caracterizado por una creencia falsa y rígida, contra la evidencia médica, de estar infestado por parásitos, acompañado generalmente por alucinaciones

Rev Méd Cient. 2021;34(1):19-20 táctiles y/o visuales. ${ }^{[2-3]}$ La paciente presentó una idea fija basada en infestación por parásitos (gusanos) donde posteriormente intenta eliminar los parásitos mediante extracción y excavación en piel, produciendo excoriación, escarificación y otras lesiones que debieron ser atendidas por profesionales de Dermatología. ${ }^{[4]}$

Es necesario reconocer la importancia de la salud mental y su repercusión en la funcionalidad humana, así como las consecuencias que puede ocasionar la falta de atención especializada. En ocasiones, el manejo de los trastornos psicopatológicos y sus consecuencias debe ser de forma multidisciplinaria, con el objetivo principal siendo el bienestar del paciente, razón por la cual resulta imperativo su cuidado desde un punto de vista holístico.

\section{REFERENCIAS}

[1] Torales J, Arce A, Moreno M, Brítez Cantero J, Adorno $\checkmark$ et al. Farmacología en Psiquiatría, Asunción, Editorial de la Facultad de Ciencias Médicas (EFACIM), Ed. 1, 2019, p. 256, ISSN/ISBN: 978-99953-67-22-0.

[2] Arce A, Torales J, Gómez N, Maggi C. La exploración psicopatológica: una introducción a la semiología psiquiátrica, Asunción, Editorial de la Facultad de Ciencias Médicas (EFACIM), Ed. 1, 2017, p. 116, ISSN/ISBN: 978-99953-67-16-9.

[3] Torales J, Arce A, Zacarías M, Girala N, Moreno M et al. La Guía TAZ de Psicofarmacología Clínica, Asunción, Editorial de la Facultad Ciencias Médicas (EFACIM), Ed. 1, 2014, p. 224, ISSN/ISBN: 978-9995367-11-4.

[4] Hernández-Figaredo P, Ramírez-Durán I. Síndrome de Ekbom o delirio parasitario. A propósito de un caso. Arch Méd Camagüey [Internet]. 2020 [citado 1 Mar 2021]; 24(6): [aprox. 8 p.]. Disponible en: http://www.revistaamc.sld.cu/index.php/amc/articl e/view/6834 